\title{
EVALUATION OF THE EXCHANGE PROGRAMS BY USING ANALYTIC HIERARCHY PROCESS
}

\author{
Bahar Celik \\ Business Administration Department \\ Dumlupinar University \\ Kutahya, TURKEY \\ E-mail: bahar.celik@dpu.edu.tr \\ Ozden Ustun \\ Industrial Engineering Department \\ Dumlupinar University \\ Kutahya, TURKEY \\ E-mail: ozden.ustun@dpu.edu.tr \\ Derya Deliktas \\ Industrial Engineering Department \\ Dumlupınar University \\ Kutahya, TURKEY \\ E-mail: derya.deliktas@dpu.edu.tr
}

\begin{abstract}
The number of university students participating in exchange programs has risen increasingly over the last decade. Student mobility, or studying at universities other than the institution at which the student originally matriculated, has been an important element in a fully rounded academic education for a long time. Therefore, the student mobility for studies and placements is important for Higher Education Institutes and university students in both national and international platform. In this study, we evaluated three exchange programs as Erasmus program, Mevlana program and Farabi program using an analytic hierarchy process (AHP) under benefits, opportunities, costs, and risks concepts. Fourteen criteria were set up, and the priorities of each criterion were appraised using the AHP method. The sample of the study consisted of 17 outgoing students from Dumlupınar University who benefited from the exchange program. Students' expectations have to be determined by considering benefit, opportunity, cost and risk (BOCR) of the exchange programs because the exchange program process has a critical importance to achieve mutual cooperations effectively among universities in both national and international platform. The evaluation process is a practical multiple-criteria decision making (MCDM) process including group decision-making with tangible and intangible criteria.
\end{abstract}

Keywords: AHP, Multiple-Criteria Decision Making, the exchange program 


\section{Introduction}

The issue of international and national student mobility has had a profound effect on policy decision-making in the higher education system of every country. Student mobility, or studying at universities other than the institution at which the student originally matriculated, has been an important element in a fully rounded academic education for a long time. There are three exchange programs at Dumlupınar University in Turkey which consists of Erasmus, Farabi and Mevlana programs, started in 2006, 2009 and 2013, respectively. Farabi program is an exchange program of students as well as teaching staff members among the Turkish higher education institutions, including universities and institutes of technology. Erasmus program encourages and supports academic mobility of students and teachers in higher education within the European Union or countries of the European Economic Area. Mevlana program is the program that includes all higher education institutions throughout the world without discriminating between the geographical borders. Both Farabi and Mevlana programs are financed by the Council of Higher Education (YÖK), and Erasmus program is financed by Center for European Union Education and Youth Programmes (Headquarters). Because of the limited budget and quota of each higher institution, the exchange program process has critical important to achieve effectively corporations among universities in both national and international platform. Therefore, the student selection process is needed to implement these goals.

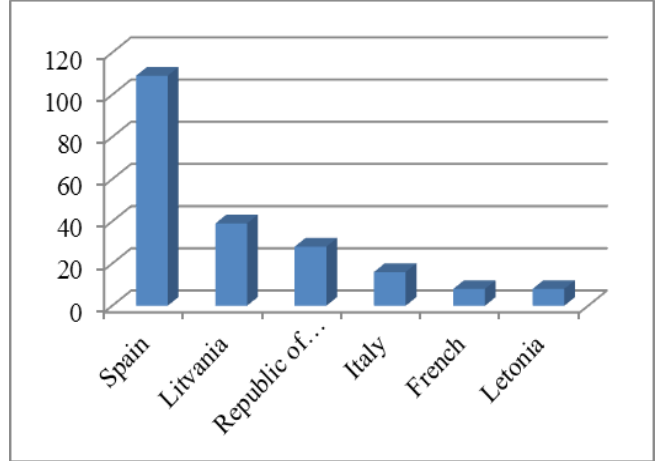

(a) The most favorite countries for Erasmus program

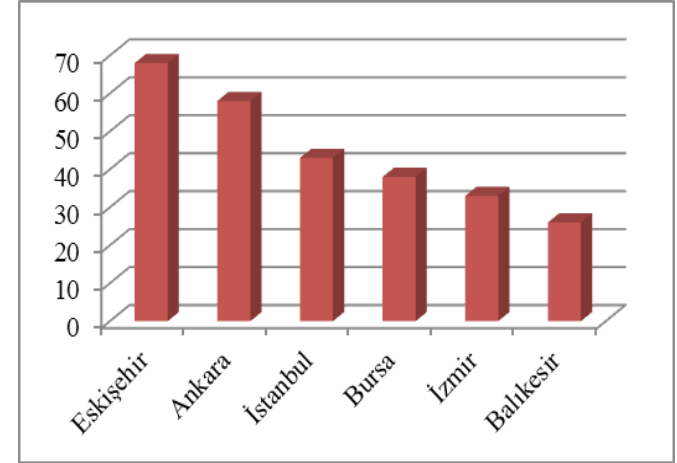

(b) The most favorite cities for Farabi program

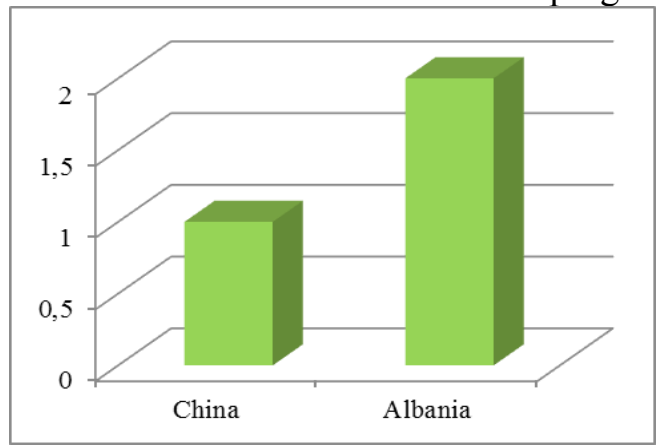

(c) The most favorite countries for Mevlana program

Figure 1 The more favorite countries or cities preferred by outgoing students 


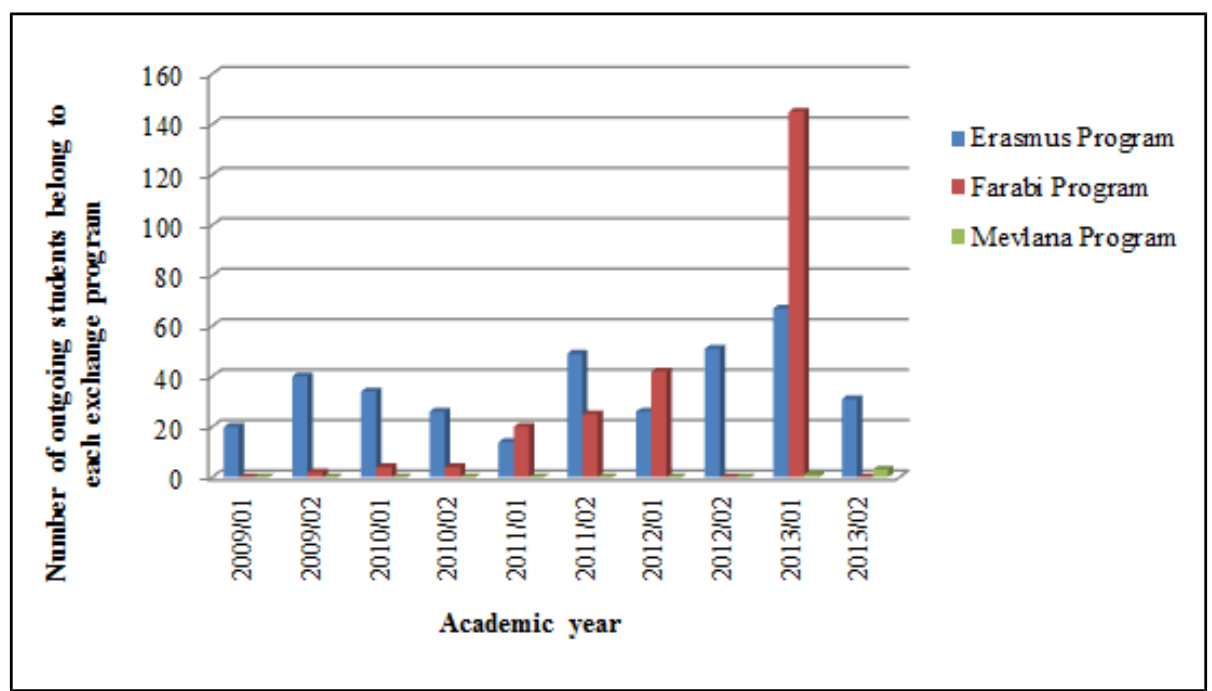

Figure 2 Dumlupınar University's outgoing students mobility

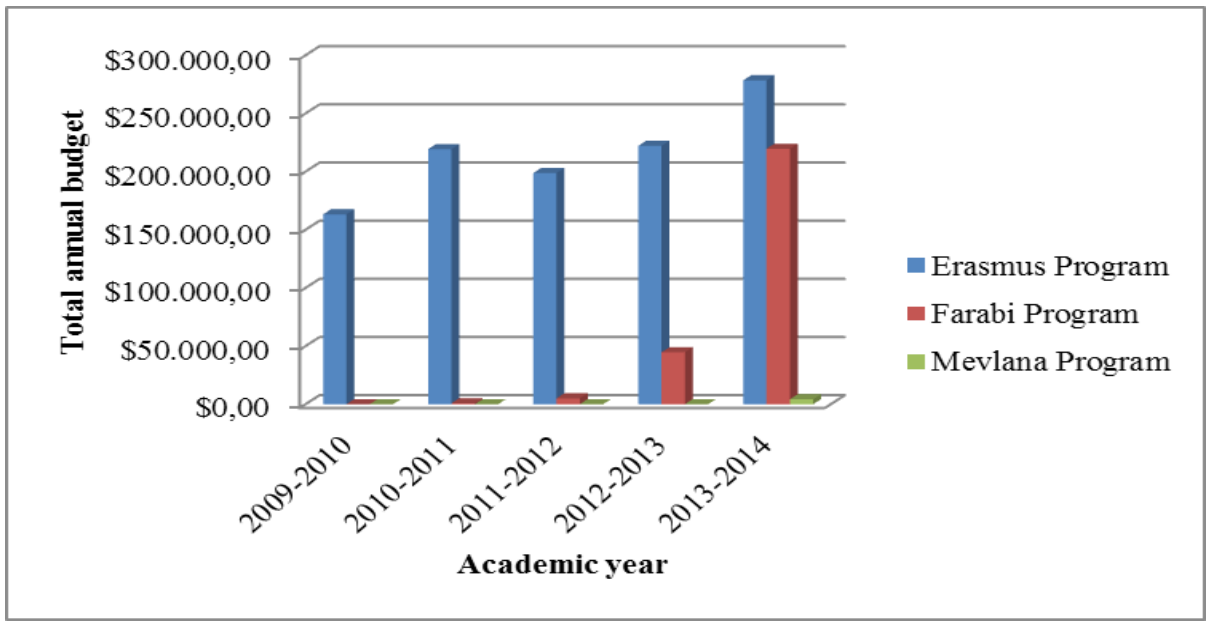

Figure 3 Total annual budget of each exchange program for outgoing students

This student selection process consists of the stage included in non-descending order of integrated GPA (Grade Point Average) score and written foreign language exam score for Erasmus/Mevlana program and the stage included in non-descending order of GPA (Grade Point Average) score for Farabi program. The most favorite countries or cities preferred by outgoing students and Dumlupınar University's outgoing students mobility and total annual budget of each exchange program are shown in Figure 1, 2 and 3, respectively.

\section{Literature Review}

In MCDM, the decision-makers generally need to compare a set of $n$ decision alternatives with respect to each criterion and construct a preference relation, and then certain techniques are applied to derive aggregated weights based on individual preference relations (Wang et al., 2012). One of MCDM techniques is AHP method introduced by 
Saaty (Saaty, 1980). In the education system of universities, there are a few studies as the student selection process (Yeh and Chang, 2003; Yeh, 2008), teaching evaluation system (Xu, 2012), course planning (Kiriş, 2014), course evaluation (Kiris et al., 2014), etc. In the literature, research on the problems of evaluation of the exchange programs by using AHP has not been studied, yet.

Students' expectations and criteria are very important to reach goals of the exchange programs. The evaluation of these programs for students is an MCDM problem. The hierarchical structure adopted in this study is shown in Figure 4. Criteria, sub-criteria and alternatives were derived through comprehensive investigation and consultation with International Relation Office Committee by using brainstorming method. As shown in Table 1, priorities of students' expectation from the exchange programs are 0.4093 for benefit criterion, 0.3110 for opportunity criterion, 0.1325 for cost criterion and 0.1471 for risk criterion. Benefit criterion is more important than the other criteria. The final priorities of Erasmus, Farabi and Mevlana programs are obtained by using AHP as $0.5255,0.1299$ and 0.3446 , respectively.

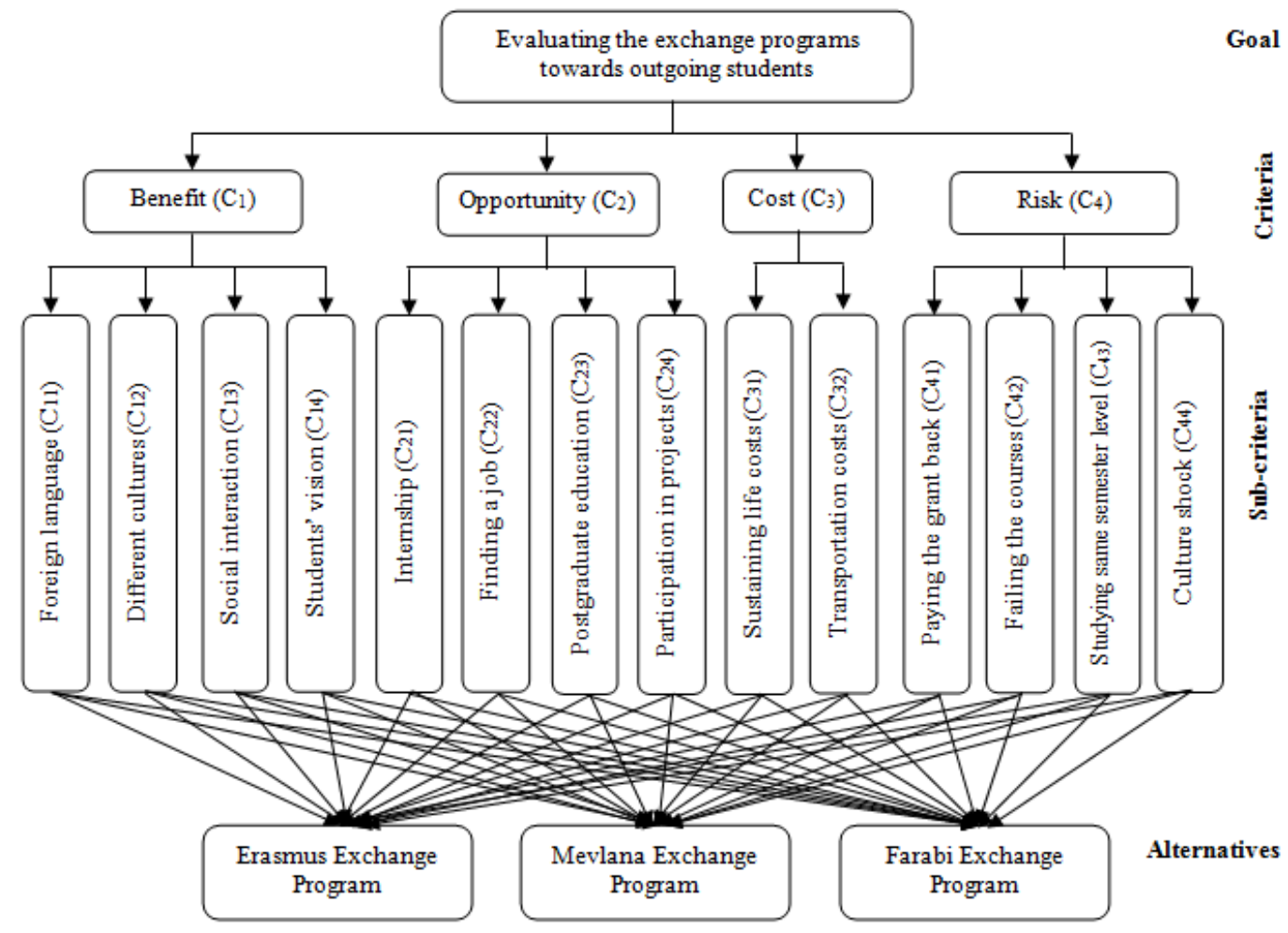

Figure 4 The hierarchy of the proposed problem

\section{Conclusions}

In this paper, a kind of methodology is used consisting of AHP method to evaluate the exchange programs. The proposed approach is implemented to 17 outgoing students from Dumlupınar University. The priorities of the exchange programs, criteria and sub-criteria are obtained by AHP. The obtained results are useful to make new bilateral agreements among universities. 
IJAHP Article: Mu, Saaty/A Style Guide for Paper Proposals To Be Submitted to the International Symposium of the Analytic Hierarchy Process 2014, Washington D.C., U.S.A.

Table 1

Relative priority of criteria and sub-criteria

\begin{tabular}{|c|c|c|c|c|c|c|c|c|c|}
\hline \multirow{2}{*}{ Criteria } & \multirow{2}{*}{ Sub-criteria } & \multirow{2}{*}{ Priorities } & \multicolumn{3}{|c|}{ Alternatives \& Priorities } & \multirow{2}{*}{$\begin{array}{c}\text { Local } \\
\text { priorities }\end{array}$} & \multicolumn{3}{|c|}{ Overall priorities } \\
\hline & & & EP & FP & MP & & EP & FP & MP \\
\hline \multicolumn{10}{|l|}{ Benefit } \\
\hline \multirow[t]{4}{*}{0.4093} & Foreign language & 0.2547 & 0.6240 & 0.0794 & 0.2966 & 0.1042 & 0.0651 & 0.0083 & 0.0309 \\
\hline & Different cultures & 0.1870 & 0.3927 & 0.1038 & 0.5035 & 0.0765 & 0.0301 & 0.0079 & 0.0385 \\
\hline & Social interaction & 0.2640 & 0.4041 & 0.2180 & 0.3779 & 0.1081 & 0.0437 & 0.0236 & 0.0408 \\
\hline & Students ' vision & 0.2943 & 0.6206 & 0.0949 & 0.2846 & 0.1205 & 0.0748 & 0.0114 & 0.0343 \\
\hline \multicolumn{10}{|c|}{ Opportunity } \\
\hline \multirow[t]{4}{*}{0.3110} & Internship & 0.1114 & 0.5647 & 0.1783 & 0.2569 & 0.0346 & 0.0196 & 0.0062 & 0.0089 \\
\hline & Finding a job & 0.4048 & 0.5683 & 0.1009 & 0.3307 & 0.1259 & 0.0716 & 0.0127 & 0.0416 \\
\hline & Postgraduate education & 0.2423 & 0.5592 & 0.1516 & 0.2892 & 0.0754 & 0.0421 & 0.0114 & 0.0218 \\
\hline & Participation in projects & 0.2414 & 0.5381 & 0.1970 & 0.2649 & 0.0751 & 0.0404 & 0.0148 & 0.0199 \\
\hline \multicolumn{10}{|l|}{ Cost } \\
\hline \multirow[t]{2}{*}{0.1325} & Sustaining life costs & 0.8171 & 0.4971 & 0.1074 & 0.3955 & 0.1083 & 0.0538 & 0.0116 & 0.0428 \\
\hline & Transportation costs & 0.1829 & 0.5263 & 0.0831 & 0.3906 & 0.0242 & 0.0128 & 0.0020 & 0.0095 \\
\hline \multicolumn{10}{|l|}{ Risk } \\
\hline \multirow[t]{4}{*}{0.1471} & Paying the grant back & 0.1558 & 0.5128 & 0.0938 & 0.3933 & 0.0229 & 0.0118 & 0.0022 & 0.0090 \\
\hline & Failing the courses & 0.3289 & 0.4983 & 0.1519 & 0.3497 & 0.0484 & 0.0241 & 0.0073 & 0.0169 \\
\hline & Studying same semester level & 0.4046 & 0.4876 & 0.1533 & 0.3591 & 0.0595 & 0.0290 & 0.0091 & 0.0214 \\
\hline & Culture shock & 0.1107 & 0.4154 & 0.0827 & 0.5019 & 0.0163 & 0.0068 & 0.0013 & 0.0082 \\
\hline
\end{tabular}

EP: Erasmus Program; FP: Farabi Program; MP: Mevlana Program

\section{Key references}

Wang, Z.J., \& Li, K.W. (2012). Goal programming approaches to deriving interval weights based on interval fuzzy preference relations, Information Sciences 193, 180-198.

Saaty, T.L. (1980). The analytic hierarchy process, New York: McGraw-Hill.

Kiriş, S. (2014). AHP and multi-choice goal programming integration for course planning, International Transactions in Operational Research, Article in Press.

Yeh, C.H. (2003). The selection of multiattribute decision making methods for scholarship student selection, International Journal of Selection and Assessment 11, 289296.

Yeh, C.H., \& Chang, Y.H. (2008). Validating Multiattribute Decision Making Methods for Supporting Group Decisions, 2008 IEEE Conference on Cybernetics And Intelligent Systems, Vols 1 and 2, 342-347.

Xu, Y. (2012). Developing a comprehensive teaching evaluation system for foundation courses with enhanced validity and reliability, Educational Technology Research and Development 60 (5),821-837.

Kiris, S., Ustun, O., \& Deliktas, D. (2014). Course evaluation and classification by using fuzzy MCDM and clustering analysis, Technics Technologies Education Management 9(1), 162-171. 